Lisbon - Malacca Port Cities Twin Conferences 2019 / 2020

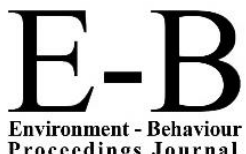
Procecdings Journal
AicQoL2020Malacca

ASLI (Annual Serial Landmark International) Conferences on QoL2020

https://www.amerabra.org; https://sspu.uitm.edu.my/cebs; https://www.emasemasresources.com/

8th AMER International Conference on Quality of Life

Mahkota Hotel Melaka, Malacca, Malaysia, 18-19 Mar 2020

(Due to the Covid-19 lockdown, paper virtually presented on 25 Mar 2020)

\title{
Safety Awareness Attitudes among Malaysian Climbers
}

\author{
Amier Hazim Zahir ${ }^{1}$, Rozita Abdul Latif ${ }^{1}$, Nor Fadzlina Nawi ${ }^{3}$, \\ Siswantoyo, M.kes, AIFO 4
}

\author{
Sports Science and Recreation, Faculty of Sports Science and Recreation, \\ 2Law, Faculty of Law, \\ Universiti Teknologi Mara, Negeri Sembilan, Malaysia \\ ${ }^{3}$ Sport Coaching, Faculty of Sport Science, \\ Yogyakarta State Universiti, Indonesia
}

amierhazim97@gmail.com, rozita.abdlatif@uitm.edu.my, nfadz644@uitm.edu.my, splc_fikuny@yahoo.com

\begin{abstract}
Outdoor recreation gives different project benefits likes gear rental and outdoor exercises. Safety awareness is related to outdoor recreation activities such as climbing and hiking. The objective was divided into three aspects, the relationship between personality and responsible behavior, the relationship between personality and attitudes, and the relationship between safety awareness attitudes and responsible behavior among climbers. This study used a quantitative method that involved 378 climbers of four mountains in Malaysia. The finding indicated that responsible behavior influences personality and a personality influences attitude. It is showed that there was a significant relationship among the climbers.
\end{abstract}

Keywords: safety awareness; personality; attitudes; responsible behavior

eISSN: 2398-4287 @ 2020. The Authors. Published for AMER ABRA cE-Bs by e-International Publishing House, Ltd., UK. This is an open-access article under the CC BYNC-ND license (http://creativecommons.org/licenses/by-nc-nd/4.0/). Peer-review under responsibility of AMER (Association of Malaysian EnvironmentBehaviour Researchers), ABRA (Association of Behavioural Researchers on Asians) and CE-Bs (Centre for Environment-Behaviour Studies), Faculty of Architecture, Planning \& Surveying, Universiti Teknologi MARA, Malaysia.

DOl: https://doi.org/10.21834/e-bpj.v5i13.2097

\subsection{Introduction}

Outdoor recreation is the basic portion of the public arena. Outdoor recreation gives different projects benefits that are ordinarily one or more prominent measures of the going with, for example, gear rental, hardware fix, retail offers of hardware, outside projects, outside occasions, and open-air exercises. Godbey (2009) stated that the sense of wellbeing is important for outdoor recreation and it needs to be recognized. Working within comparatively natural areas, with nearby outdoor recreation areas and amenities, allows a person to gaze at nature, besides provides him with health benefits. According to Esfahani (2015), extreme sports become the most popular activity in nature. Several activities can be done in nature, such as climbing, trekking, and crosscountry activities. Today, the demand for outdoor recreation is blooming and it is well-known to anyone even to those who are modestly familiar with the situation (Marion Clawson \& Knetsch, 2011). Outdoor recreation is seemingly less publicized but no less impressive as it has been immensely heightened interest as a field for professional study in the last decade or so.

People who are involved in outdoor recreation tend to face the risk of injury and the main factor is safety awareness. Susanto (2017) stated that the number of women killed in mountaineering is significantly lower than males (3.5:1). This is because males are inclined to be exposed more in undertaking extreme activities as compared to women. The awareness about safety is still

eISSN: 2398-4287 @ 2020. The Authors. Published for AMER ABRA CE-Bs by e-International Publishing House, Ltd., UK. This is an open access article under the CC BYNC-ND license (http://creativecommons.org/licenses/by-nc-nd/4.0). Peer-review under responsibility of AMER (Association of Malaysian EnvironmentBehaviour Researchers), ABRA (Association of Behavioural Researchers on Asians) and cE-Bs (Centre for Environment-Behaviour Studies), Faculty of Architecture, Planning \& Surveying, Universiti Teknologi MARA, Malaysia.

DOI: https://doi.org/10.21834/e-bpj.v5i13.2097 
lower due to their perceptions of it. There was a piece of news reported regarding the incident where a lady fall from a height of 15.24 meters when climbing down from the hill with her friends (Farhana 2019). This incident happened when a person did not take any precautious safety measurement seriously when undertaking outdoor activities such as hiking and trekking.

The incidence of accidents associated with mountaineering has increased with the increment of adventure tourism in the mountains (Windsor et. al, 2009). Furthermore, the incidents occurred due to the inherent risks and hazards associated with its operation, especially in a high-altitude environment (Musa, Hall, \& Higham, 2004). Therefore, to minimize the number of injuries in the mountains, care should be taken for more responsible mountaineering activities that have a direct impact on safety. By focusing more on safety, it could lead to the creation of healthy climbing destinations that improve health through to the promotion of physical activities and could lead to an increasing number of climbers with various skills and personal background.

\subsection{Literature Review}

Safety awareness is the process in which hazards that are presented in an activity that can be identified and the risk involved can be estimated too. In an outdoor adventure context, it will require an assessment of the competences and limitations of the participants, the equipment being used, the environment/location in which the activity takes place and the hazards inherent in the activities (Thomas, 2006).

Hwang et al (2000) stated that many health problems and injuries are caused by not practicing safety awareness practices. Younger people tend to be more aware of safety as compared to older people. This is most likely because when the younger people commence outdoor activities, they have a different viewpoint on the equipment and procedure to be used. A person who has more exposure to safety awareness is more likely to alert with safety issues like equipment malfunction and inexperienced in handling the equipment (Arora, 2012). It was found that there was no difference in personality characteristics between mountain climbers and alpine climbers (with several experiences at altitudes greater than $8,000 \mathrm{~m}$ ). It is believed that mountain and al pine climbers generally alike in terms of personality profile traits such as emotional stability, extraversion, seeking a thrill, conformity to social norms and experience by socialized means (Monasterio et al. (2014). Personality also can be denoted as individuals' characteristic patterns of thought, emotion, and behavior together with the psychological mechanisms - hidden or not - behind those patterns. There are five types of personality characteristics of climbers.

Table 1.0: Five Personality Trait

\begin{tabular}{ll}
\hline Personality & Characteristic \\
\hline Neuroticism & Lack of psychological adjustment. \\
Extraversion & Demonstrates sociability, cheerfulness, and optimism. \\
Openness to & Independence, curiosity to explore new ideas, creativity, and appreciation of \\
experience & the arts. \\
Agreeableness & Good-natured, forgiving, trustworthy and cooperative. \\
Conscientiousness & Hardworking, self-disciplined, strong-willed, deliberate and reliable \\
\hline
\end{tabular}

Moreover, attitude and behavior also lead to safety awareness which has shown a relationship between environmental attitude and environmentally responsible behavior (Backlund \& Williams, 2003; Schultz \& Zelezny, 1998; Tarrant \& Cordell, 1997). People with a positive attitude will behave in a good way and take precautions actions to stay safe. People with a negative attitude tend to have negative behavior and belief which will lead more to danger and risk. As attitudes influences behavior thus, safety awareness attitudes will influence individual behavior (Jackson, 2014).

With the rapid growth of mountaineering activities, there is an increase in responsible mountaineering behavior among the climbers. Bear, Manning, and Izard (2003) believe that "responsible behavior entails self- motivation and self-guidance, and not obedience and compliance to rules merely in response to external supervision, rewards, and punishment". Safety awareness has also been affected by the responsible behavior of climbers.

The accidents and injuries among the climbers occurred due to the individual did not take any precautious safety measurement seriously when doing outdoor activities such as hiking and trekking. It occurs because of the individual's attitude or behavior that leads to the problem. Each individual has his or her attitudes or behavior towards safety awareness when conducting activities especially in extreme activities (Wolf-Watz, (2010). This study is aimed to identify safety awareness attitudes among Malaysian climbers.

\subsection{Methodology}

For this study, it used a quantitative method as it is the most appropriate method to be utilized. Quality measures that are typically considered are objectivity, reliability, and validity. A descriptive study or survey research by questionnaire is been used to describe the characteristics of a group or population (Fraenkel et., 2012). A descriptive study establishes only associations between variables. 


\subsection{Sample}

The population for this study was based on purposive sampling on four mountains in Malaysia (Mount Jerai, Mount Ledang, Mount Nuang, Mount Datuk). Each of the mountains represents the north, south, east and west of Peninsular of Malaysia (Sabah and Sarawak are not in the list because of (distance) limitation). As being reported in http://www.wildlife.gov.my/index.php/en/ (Official Website of National Park), each of the mountains is having the average number of visitors around 15000 per year. The sample size of this study is 377 , however, 10 percent of the total sample size was added as a backup for data loss, uncompleted and unreturned questionnaires (Enders 2003). Thus, the actual sample size of this study is 387 respondents.

\subsection{Instrumentation}

The questionnaire was adopted from Esfahani (2015). The questionnaire was confined from 6 sections to 4 sections only. Section $A$ is for the demographic profile, section B is for responsible behavior related to safety with the Cronbach alpha of 0.789 and section $\mathrm{C}$ is for attitudes (knowledge, awareness, and commitment of mountain climbing) with the Cronbach alpha of 0.837 . Section $\mathrm{D}$ is to measure five types of personality characteristics (Extraversion, Agreeableness, Conscientiousness, Neuroticism, and Openness to Experience) with the Cronbach alpha of 0.782 . The Cronbach alpha for the survey was reliable to be utilized. It was stated that Alpha values between 0.5 to 0.6 show sufficient reliability whereas an alpha value of 0.7 or above was acceptable and a good indication of reliability (Nunnally \& Bernstein, 1994). The survey was given in two languages; the Malay and English language. The investigation is utilized with a Likert 5-point scale, with "strongly disagree" (1) to "strongly agree" (5).

\subsection{Findings}

These results were derived from 387 respondents. The analysis of data described the safety awareness attitudes among Malaysian climbers. The analysis of data carried out by using (SPSS) version 25.0. There were 205 (53.0) male respondents and 182 (47.0) female respondents who participated in this study. Most of the respondents are in the age of 20 to 29 years old and the rest are from the age of 19 and below and 30 and above. The percentage shown in the table is among the age range of 19 and below 20 (5.2), 20-29 years old 297 (76.7) and 30 years and above 70 (18.1).

\subsection{Personality of Climbers}

Personality was represented in five dimensions: Agreeableness, Extraversion, Conscientiousness, Neuroticism, and Openness to Experience.

Table 4.0:The personality of Climbers $(N=387)$

\begin{tabular}{lcc}
\multicolumn{3}{c}{ Table 4.0:The personality of Climbers $(N=387)$} \\
\hline Climbers Personality & Mean & SD \\
\hline Neuroticism & 3.96 & 0.67 \\
Extraversion & 4.03 & 0.66 \\
Openness & 3.89 & 0.66 \\
Agreeableness & 4.20 & 0.57 \\
Conscientiousness & 4.07 & 0.59 \\
\hline
\end{tabular}

Based on the table above, the highest mean of personality is "agreeableness" with $M=4.20(S D=0.57)$ which influenced by male around the age of 20-29 years old and the second is "conscientiousness" with $M=4.07$ (SD $=0.59$ ) which influenced by male with the age of 20-29 years old. Next is "extraversion" with $M=4.03(S D=0.66)$ which influenced by male with the age of 20-29 years old and followed by "neuroticism" with $M=3.96(S D=0.67)$ influenced by male with the age of 20-29 years old and the last one is "openness" with $M=3.89$ ( $S D=0.66$ ) influenced by male with the age of 20-29 years old.

\subsection{Responsible Behavior among climber}

It focusses on the specific responsible behavior that needs to be carried to protect the climbers. Based on table 4.1, the highest mean of responsible behavior is "food and drink requirement" with $\mathrm{M}=4.25(\mathrm{SD}=0.76)$ and the second is "equipment requirement" with $\mathrm{M}=4.14(\mathrm{SD}=0.99)$. Next is "clothing requirement" with $\mathrm{M}=4.14(\mathrm{SD}=0.70)$ and followed by "obedience requirement" with $\mathrm{M}=3.95(\mathrm{SD}=0.44)$.

Table 4.1: Responsible Behavior ( $N=387$ )

\begin{tabular}{lcc}
\hline \multicolumn{1}{c}{ Safety Item } & Mean & SD \\
\hline Food and Drink requirement & 4.25 & 0.76 \\
Equipment requirement & 4.14 & 0.99 \\
Clothing requirement & 4.14 & 0.70 \\
Obedience requirement & 3.95 & 0.44 \\
\hline
\end{tabular}




\subsection{Relationship between Responsible Behavior and Personality}

Table 4.2: Relationship between Responsible Behavior and Personality

\begin{tabular}{|c|c|c|c|c|c|}
\hline \multirow{2}{*}{$\begin{array}{l}\text { Responsible } \\
\text { Behavior }\end{array}$} & \multicolumn{5}{|c|}{ Personality } \\
\hline & Neuroticism & Extraversion & Openness & Agreeableness & Conscientiousness \\
\hline Food \& Drink & $.546^{* \star}$ & $.443^{* \star}$ & $.533^{* *}$ & $.511^{\star \star}$ & $.352^{* *}$ \\
\hline Equipment & $.427^{* *}$ & $.476^{* *}$ & $.500^{* *}$ & $.413^{* *}$ & $.470^{* *}$ \\
\hline Clothing & $.360^{* \star}$ & $.413^{* *}$ & $.460^{* *}$ & $.392^{* *}$ & $.347^{* \star}$ \\
\hline Obedience & $.425^{\star \star}$ & $.477^{\star *}$ & $.380^{* *}$ & $.482^{* *}$ & $.562^{* *}$ \\
\hline
\end{tabular}

In this study, the Pearson correlation was used to see whether there is a relationship between responsible behavior and personality among climbers. The table above shows that there is a significant relationship between responsible behavior and personality among climbers because of the p-value for all items is 0.00 . Table 4.2 above shows the relationship between responsible behavior and personality for each factor. The highest relationship is between obedience and conscientiousness with $r=$ $0.56(p=0.00)$ where second-highest relationship is between food \& drink and neuroticism with $r=0.55(p=0.00)$ and the thirdhighest is between food $\&$ drink and openness with $r=0.53(p=0.00)$. The lowest relationship was between clothing and conscientiousness which is $r=0.35(p=0.00)$, the second-lowest relationship is between clothing and neuroticism which is $r=$ $0.36(p=0.00)$ and the third-lowest relationship is between obedience and openness with $r=0.38(p=0.00)$.

\subsection{Relationship between Responsible Behavior and Personality and Safety Awareness Attitudes among Climbers}

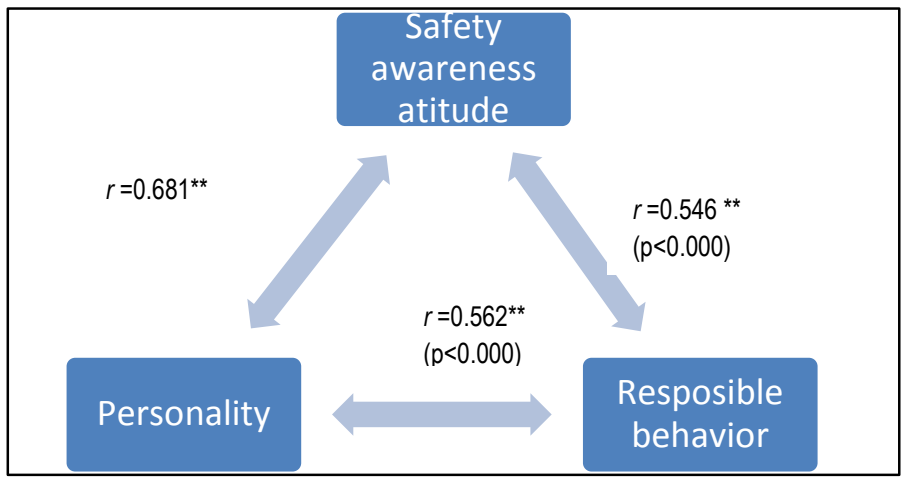

* Significant at the $<0.05$ level ( 2 tailed)

Figure 1.0: Relationships between safety awareness attitude, personality, and responsible behavior.

Figure 1.0 shows the relationship between safety awareness attitudes and behavior. From the result, it shows that the relationship between safety awareness attitudes and behavior is a sign therefore it rejects the null hypothesis ( $\mathrm{Ho}$ ). It also shows that there is a significant relationship between responsible behavior and personality, and therefore it rejects the null hypothesis (Ho).

\subsection{Discussion}

Previous studies have shown that there is an incrementing number of climbers and those who were injured and died during climbing. The current study explores the relationship between responsible behavior and personality and the relationship between personality and attitudes. One of the findings showed that male climbers tend to be more exposed to safety awareness as compared to female climbers. This finding is following a study by Bhim and Jayanta (2010). Then, the highest percentage of respondents' age range is $20-29$ years old which proves that the higher the age range, the higher the awareness toward safety and this finding supports the findings from Aminrad et. al, (2010 \& 2011). This means when age increases, safety awareness will increase too. Next, the highest percentage of respondents' marital status is single. The single person tends to have less commitment compared to the married person. They are spending their time doing extreme activities rather than a married person who mostly spent their time with family.

\subsection{Personality of Climbers}

The findings are aligned with the findings of past research by Esfahani (2015). Agreeableness has the highest mean score as compared to other factors of personality. It shows that climbers tend to have agreeableness personality when doing the activity. 
Referring to the findings, the highest total means score for personality was agreeableness which $M=4.20$ ( $S D=0.57$ ) followed by conscientiousness $\mathrm{M}=4.07$ ( $S D=0.59)$, extraversion $\mathrm{M}=4.03(\mathrm{SD}=$, neuroticism $\mathrm{M}=3.96(\mathrm{SD}=0.67)$, and openness to experience which $M=3.89$ ( $S D=0.66)$. Furthermore, as reported by Esfahani $(2015)$, climbers with a high level of agreeableness can achieve higher safety awareness attitudes. It is proven that climbers can easily be affected by personality. Agreeableness plays an important role for the climbers to reinforced their impressions towards the activity. Moreover, agreeableness can easily change the climbers' perception of the activity. Climbers trust easily those who have agreeableness personality and this influences them to be more confident in the activity.

The findings of this study also supported findings by Judge (2002), where agreeableness should be related to happiness because agreeable individuals have greater motivation to achieve interpersonal intimacy, which should lead to greater levels of well-being. Indeed, they found that agreeableness was positively related to life satisfaction. Assuming these same communal motivations exist on the job, then the same process should be operated for job satisfaction. Organ and Ling (1995) agreed that commenting Agreeableness "involves getting along with others in pleasant, satisfying relationships".

In the current study, it was found that personality traits of agreeableness, openness to experience, extraversion, conscientiousness and neuroticism influence attitude. These findings are consistent with the study by Hirsh and Dolderman (2007) which found that high levels of agreeableness and openness to experience relate to great environmental concern. They also found that neuroticism is related to high levels of environmental concern. Moreover, Mayer and Frantz (2004) highlighted that people with higher agreeableness and openness are possessed to experience a greater connection with nature which predicts their pro-environment attitude. Swami (2011) also suggested that conscientiousness can positively and directly influence pro-environmental attitudes.

\subsection{Responsible Behavior Among Climber}

Refer to the findings, the highest total mean score for responsible behavior was food and drink which $M=4.25(S D=0.76)$ followed by equipment requirement $\mathrm{M}=4.14(\mathrm{SD}=0.99)$, clothing requirement $\mathrm{M}=4.14(\mathrm{SD}=0.70)$ and obedience requirement which $\mathrm{M}=3.95$ $(S D=0.44)$. these were aligned with the findings of past research by Esfahani (2015), the researcher stated that food and drink one of the important reasoned that been emphasize by the climbers followed by equipment requirements. It is proved that climber's emphasis ore in terms of food and drinks when doing outdoor activity also the readiness of the equipment for the activity (Ong and Musa, (2011).

\subsection{Relationship Between Responsible Behavior, Personality and Safety Awareness Attitudes Among Climbers}

The current study has found a significant positive relationship between responsible behavior and personality. The finding is consistent with previous research on moving personality development by Jackson (2014). It is stated that any modification/changes in personality may also affect /influence outcomes-after all, attainment of some outcome goal is one of the main reasons people give for changing behavior in the first place to predict outcomes. Thus, the individual's personality is affected by the behavior /The behavior will affect an individual's personality.

Several behavioral models were used to investigate the relationship between attituded and behavior which then revealed how attitude can influence behavior and showed there was a relationship between environmental attitude and environmentally responsible behavior (Backlund \& Williams, 2003; Schultz \& Zelezny, 1998; Tarrant \& Cordell, 1997). Therefore, the relationship between attitude towards behavior and responsible mountaineering behavior is examined in the current study. The current study found a significant relationship between personality and attitude towards the behavior. It indicates that four personality dimensions (agreeableness, openness to experience, extraversion, and conscientiousness) are positively related to attitude towards behavior, except for neuroticism. Therefore, climbers with a high level of agreeableness, openness to experience, extraversion and conscientiousness possess a higher level of attitude that links to the safety awareness attitudes.

Also, Markowitz (2012) explored the relationship between pro-environmental action and broad personality traits and showed that individuals' environmental attitudes and connections to nature fully mediate the relationship between openness to experience and pro-environment behavior. In the current study, climbers with characteristics such as good-natured, courteous, friendly, trusting (agreeableness), original, creative, daring, independent (openness to experience), sociable, talkative, fun-loving, affectionate (extraversion), dutiful, careful, reliable, organized, hardworking (conscientiousness) are likely to have better knowledge about pre-climb instructions, pre-climb requirements, mountain climbing safety practices, mental preparation before climbing and skills required for climbing.

The study also found a significant positive relationship between safety awareness attitudes and behavior. The finding is consistent with previous research by Hwang et al (2000). It is stated that change in attitudes may also influence outcomes-after all, attainment of some outcome goal is one of the main reasons people give for changing behavior in the first place to predict outcomes. Safety awareness attitudes will affect individual behavior.

\subsection{Conclusions and Recommendations}

In the conclusion, this study provides support to the role of mountaineering education that should be disseminated by guides, other climbers, friends, and media to positively influence mountaineering attitudes and also to increase responsible mountaineering behavior. From the results, it indicates that the safety awareness attitudes among the climbers that basically could help the climbers to be more aware of the safety issues especially when undertaking the extreme activity and also can help to reduce the number 
of incidents occur that involved climbers. Thus, it is hoped that this study could change people's perceptions of extreme activities such as climbing, hiking, and mountaineering.

The researcher would like to give some recommendations for future research. It is recommended that future researchers use the right respondent like climbers as a subject. The researcher should consider the respondents, venue, environment and time to collect the data. This can affect the responses given by the respondents if they are not selected carefully by the researcher. On the other hand, the researcher should consider investigating the respondents' perspective as the consumer of the product. It could help the respondents to give a clear picture of the endorser and the product.

\section{Acknowledgment}

The author I would like to thank the following people for their help and support: My major professor, Dr. Rozita for all of her help and for never giving up on me. All my family and friends who never stopped believing in me, even when I did, thank you. I could not have done this without all of you.

\section{References}

Arora, S., Sevdalis, N., Ahmed, M., Wong, H., Moorthy, K., \& Vincent, C. (2012). Safety skills training for surgeons: a half-day intervention improves knowledge, attitudes, and awareness of patient safety. Surgery, 152(1), 26-31.

Bear, G. G., Manning, M. A., \& Izard, C. E. (2003). Responsible behavior: The importance of social cognition and emotion. School Psychology Quarterly, 18(2), 140.

Clawson, M., \& Knetsch, J. L. (2013). Economics of outdoor recreation. Routledge.

Godbey, G. (2009). Outdoor recreation, health, and wellness: Understanding and enhancing the relationship.

Hirsh, J. B., \& Dolderman, D. (2007). Personality predictors of consumerism and environmentalism: A preliminary study. Personality and individual differences, 43(6), 1583-1593.

Hwang, S. A., Gomez, M. I., Stark, A. D., John, T. L. S., Pantea, C. I., Hallman, E. M., ... \& Scofield, S. M. (2000). Safety awareness among New York farmers. American journal of industrial medicine, 38(1), 71-81.

Jackson, J. J., \& Allemand, M. (2014). Moving Personality Development Research Forward: Applications Using Structural Equation Models. European Journal of Personality, 28(3), 300-310. DOl:10.1002/per.1964

Judge, T. A., Heller, D., \& Mount, M. K. (2002). Five-factor model of personality and job satisfaction: A meta-analysis. Journal of applied psychology, 87(3), 530.

Mahdi Esfahani, S. K. (2015). Measuring responsible behavior related to safety and security and its antecedent among climbers on Mt Kinabalu. Mountaineering Tourism.

Markowitz, E. M., Goldberg, L. R., Ashton, M. C., \& Lee, K. (2012). Profiling the "pro-environmental individual": A personality perspective. Journal of personality, 80(1), 81-111.

Monasterio, E., Alamri, Y. A., \& Mei-Dan, O. (2014). Personality characteristics in a population of mountain climbers. Wilderness \& Environmental Medicine, 25(2), 214-219.

Musa, G., Hall, C. M., \& Higham, J. E. (2004). Tourism sustainability and health impacts in high altitude adventure, cultural and ecotourism destinations: A case study of Nepal's Sagarmatha National Park. Journal of Sustainable Tourism, 12(4), 306-331.

Ong, T. F., \& Musa, G. (2011). An examination of recreational divers' underwater behavior by attitude-behavior theories. Current Issues in Tourism, 14(8), 779795.

Susanto, N., WP, S. N., \& Rizkiyah, E. (2018). Evaluating Risk Perception based on Gender Differences for Mountaineering Activity. In E3S Web of Conferences (Vol. 31, p. 09028). EDP Sciences.

Thomas, K., Aguar, P., Kawasaki, H., Morris, J., Nakanishi, J., \& Savage, N. (2006). Research strategies for safety evaluation of nanomaterials, part VIII: international efforts to develop risk-based safety evaluations for nanomaterials. Toxicological Sciences, 92(1), 23-32.

Windsor, J. S., Firth, P. G., Grocott, M. P., Rodway, G. W., \& Montgomery, H. E. (2009). Mountain mortality: a review of deaths that occur during recreational activities in the mountains. The postgraduate medical journal, 85(1004), 316-321.

Wolf-Watz, D. (2010). Outdoor Recreation and Environmentalism. 